\title{
Micro Retail Enterprises in China: Challenging the Stereotype
}

\author{
Walter Huber, Martin Brady, Qin Deng, Xinxin Wei, Man Zhang, Ruizhen Zhang, Xiaoxuan Zhang \\ Muskingum University, Ohio, USA
}

\begin{abstract}
Micro Retail Enterprises (MREs) are ubiquitous in cities and countryside of China. They are however generally ignored in the literature and generally lumped with Small and Medium Enterprises (SMEs). MREs are unique in a number of key ways and how they have responded to the slowing economy in China has yet to be examined. This paper seeks to shed light on how MREs have dealt with the changes in China's economy. Not all sectors of the economy have responded the same to China's "new normal" growth during the past year. The authors conducted 1,440 surveys of MREs in seven cities and gathered data on access to bank loans, acceptance of credit cards, which business strategies they adopted, and which government programs would provide the most assistance to them. Results suggest that MREs are much more likely to have access to loans, use credit cards, and employ sophisticated business strategies than previously thought.
\end{abstract}

Keywords: micro retail enterprise, China's retail sector, bank loans, credit card use in China

China has long been characterized by fast economic growth and while it is still growing at a pace much of the developed world economies can only envy, there is no doubt that China's growth is slowing. As the University of Pennsylvania's Warton School's Public Policy Pacific Asia blog argued,

For much of the past year, Chinese President Xi Jinping has been urging his country to stay cool in the face of China's "new normal" of slower economic growth. "We must boost our confidence, adapt to the new normal conditions based on the characteristics of China's economic growth in the current phase and stay cool-minded", he said last May. On January 19, the National Bureau of Statistics announced that the country's 2014 GDP growth rate came in at $7.4 \%$ - slightly higher than an expected rate of 7.3\%, but below Beijing's 7.5\% target range. This year's target is set even lower at 7\%. (University of Pennsylvania's Warton School, 2015)

The new normal of comparatively slower economic growth has proven real. The Chinese economy's $6.7 \%$ average economic growth rate in 2016 was the lowest rate of growth for the Chinese economy since 1990 (BBC News, 2017).

Corresponding author: Walter Huber, Ph.D., professor of Political Science, Department of Political Science and director of the Center for Regional Planning and Development, Muskingum University, Ohio, USA; research fields: education policy, economic policy, environmental policy, political economy, comparative public policy.

Martin Brady, MAcc, CPA, CMA, CFM, professor of Accounting, Department of Economics, Accounting, and Business, Muskingum University, Ohio, USA; research fields: financial accounting and managerial/cost accounting.

Qin Deng, B.A. candidate, Mathematics and Economics, Muskingum University, Ohio, USA; research fields: economic policy, mathematics.

Xinxin Wei, B.A. candidate, Accounting, Muskingum University, Ohio, USA; research fields: economic policy, accounting.

Man Zhang, B.A. candidate, Digital Media Design, Muskingum University, Ohio, USA; research fields: marketing, China's economy.

Ruizhen Zhang, B.A. candidate, Business Management, Muskingum University, Ohio, USA; research fields: economic policy, management.

Xiaoxuan Zhang, B.A. candidate, Business Management, Muskingum University, Ohio, USA; research fields: economic policy, management. 
Given the size of China' economy, the effect of this slowing growth will reverberate around the world in a number of ways. The effects inside China will be even greater and more immediate. China has responded to the slowing growth in a proactive fashion and is committed to doing all possible to mitigate any number of negative externalities that might arise from slowing growth. So far, the Chinese government has put forth a number of policies and backed them with a substantial amount of public money but most efforts are intended to make changes at the macroeconomic level such as the "One Belt One Road" initiative (an international trade route linking China to the Middle East and Europe) (Tsao, 2015). While the government has put forth some policies intended to assist small businesses including a reform to the Value Added Tax (VAT) intended to decrease tax payments for smaller mainland firms (Ren, 2016). While policies such as these are no doubt of benefit to some, there are several categories of businesses being left out.

\section{Effects of a Slowing China}

The effect of the economic slowdown in China on each business sector is not the same. According to the Financial Times, China's official manufacturing purchasing managers' index fell to 49 in February 2016 from 49.8 in January 2016, equaling its weakest since February 2009 and the seventh straight month of decline (Waldmeir, 2016). However, not all sectors are faring the same and broad economic data can hide as much as it reveals. For example, the catering and the retail industries present unusual trends. China's National Bureau of Statistics released data that demonstrated that in 2015, China's catering industry sales grew $11.7 \%$. Despite overall downward pressure on the economy and a tightening of official's use of luxury services, the catering industry is growing (Feng, 2016).

Overall, China's economy has been slowing. China's economy grew by $6.7 \%$ in 2016 , compared with $6.9 \%$ a year earlier, according to official data, marking its slowest growth since 1990 (BBC News, 2017). The slowdown in China's growth has become a major worry to the business sector. A recent survey of CFO of Chinese companies found that $48 \%$ of interviewees considered the economic slowdown as the major macro-economic issue that held the potential to undermine their business (J.P. Morgan, 2016).

Growth of the retail sector overall has declined steadily since 2012. There is pressure on retail stores including department stores and specialty retails in order to keep sales high. However, the growth of club stores and convenience stores has placed pressure on traditional retail stores to maintain profitability (2016 Present Situation Analysis of China's Retail Industry and Trend of Development, 2016). According to the Report on the Development of China's Convenience Store, convenience stores still show potential for growth, albeit slower, as the entire retail industry grows and inevitably slows from the economic slowdown. "Retail sales in China rose 9.5 percent year-on-year in January-February of 2017, it was the weakest growth on record from 2010 to 2017" (China Retail Sales, 2017). In addition, new entrants concentrated on low-tier cities where competition is less intense. Comprehensive analysis of the data shows that the convenience store industry is still in its second expansion (Gai, 2015). While several sectors of retail have outperformed the industry as a whole, overall growth is slowing.

\section{Small and Very Small Enterprises}

Small and Medium Enterprises (SMEs) are an important component to the overall makeup of all economies but may play an especially important one in China during periods of slowing economic growth. After examining the economic impact of SMEs on the Chinese economy, Wang notes: "Another crucial effect 
of SMEs in China is their contribution to the improvement of the rate of employment. SMEs are the main channel for job creation and lessen the unemployment pressure" (Wang, 2004, p. 36). The ability of SMEs to mop up recently laid-off state workers is especially important at a time when China is seeking to reduce excess capacity in a number of sectors dominated by state-owned firms such as coal mining and steel manufacturing. Since the reforms of 1978, SMEs have grown to become an essential part of the Chinese economy. In terms of China's private sector, it is the main driver of economic growth: SMEs contributed about 59\% of GDP and represented more than $65 \%$ of the imports and exports in China (Liu, 2008). Although SMEs play an outsized role in the economy, the government does not currently have adequate legislation to support the growth of SMEs which is correlated with China's SMEs' generally having a lower degree of specialization and cooperation in production areas (Dudovsky, 2012). The lack of government policies regarding SMEs has created unintended challenges and barriers for SMEs' growth (Mu, 2003).

Problems with crafting policy proposals to assist SMEs are compounded by the broad range of economic activity SMEs in China cover. Originally, in China, the definition of SME was

Written in the Law of the People's Republic of China on Promoting Small and Medium-Sized Enterprises. In accordance with Article 2 of the Law, SMEs refer to various enterprises which are established with the Territory of the People's Republic of China (PRC), and owned by different entities and in various forms, with small and medium production and operation size, excluding those enterprises whose 25 percent stock ownership or investment are held by a large-sized enterprise. (Wang, 2004, p. 35)

The most recent change to the Law of the People's Republic of China on Promoting Small and Medium-Sized Enterprises was in 2017. SMEs engaged in manufacturing are defined as having fewer than 100 employees and assets of no more than 30 million RMB. For other industries, SMEs are defined as having fewer than 80 employees and assets of no more than 10 million RMB (Liu, 2008).

Small firms and enterprises are beginning to play an increasing and important role in the development of China's economy (Siu, 2001). CBRC (China Banking Regulatory Commission) states that the official number of SMEs in China exceeded 12 million in 2005 which accounted for $99 \%$ of private sector companies and they contributed more than $50 \%$ of the GDP in 2005 , more than $48 \%$ of overall tax collected by the government came from SMEs in China (CBRC, 2006). Most SMEs operate mainly in labor-intensive small and medium industries because they lack access to technology and funding ( $\mathrm{Li}$, Guo, Liu, \& Li, 2007). Liu and Huang (2016) indicated another distinct characteristic that Chinese entrepreneurs tend to operate businesses that are small in scale and the majority of entrepreneurs hired no employee outside of their families.

SMEs in China face a lot of barriers and challenges. They have few supportive guidelines and laws (Li et al., 2007). The literature maintains that obtaining a bank loan is a big obstacle in financing SMEs in China; they have a record of weak technological innovation and limited options for financing. It is suggested that these factors have limited SMEs' growth in China and stifled innovation (Shi, Peng, Liu, \& Zhong, 2008). SMEs' access to financing is often blocked because of a lack of knowledge about their credit-worthiness. Three related reasons for this are thought to be that: banks generally have little information about SMEs' credit records; SMEs do not have strong incentives to open and maintain credit lines; and the transaction cost of future loans is not generally seen to be influenced by maintaining loans in the present (Mu, 2003). John Dudovsky argues that most banks do not want to issue loans to SMEs, because they assume that SMEs are riskier than other large companies (Dudovsky, 2012). According to OECD report in 2006, the Chinese government has realized and recognized the importance of the private sector for economic growth, job creation, and its effects on the 
infrastructure, therefore the government has started to support them in the same way as publicly-owned companies.

To its credit, the PRC has adopted a number of effective measures to assist SMEs in general. For example, China's Ministry of Science and Technology adopted the Law of Small and Micro Enterprises Promotion. The law created a number of programs for SMEs including financial subsidies, tax credits, preferential procurement, loan assistance, business counseling, and entrepreneurial training programs (Liu \& Huang, 2016). Policies of these sorts will be helpful to a broad group of companies but there is at least one sector that has received scant attention: Micro Retail Enterprises (MREs).

A MRE in China is defined by the authors of this paper as a private owner-operated non-franchise retail business with a single location with fewer than five employees outside of members of the owner's family. They are ubiquitous in China and take the form of venders setting up shop on the sidewalk, small souvenir stands, specialty retail stores (e.g. flower shops), convenience stores, small restaurants, service providers (e.g. barbers), and venders of household goods (e.g. plumbing supplies). These entrepreneurs have different problems than comparatively larger SMEs. To cite one instance, unpaid bills have become a problem in China once again (Liu \& Huang, 2016). This is of concern to the broader economy since triangular debt (solvent companies being dragged into bankruptcy because insolvent creditors do not pay their accounts payable bills in a timely fashion) exacerbated the Asian Financial Crisis of the 1990s. This is less of a concern for MREs than SMEs since they are less likely to have accounts payable accounts.

By surveying 1,440 MREs in seven Chinese cities, this paper examines how MREs in general, and by sector, have been affected by and responded to the new normal of slower economic growth. Understanding how these businesses are affected and coping is of particular importance because along with being a pressure release for layoffs in the SOE (state-owned enterprises) sector, they are an engine of growth. In China, the majority of privately held firms are being as small-scale family owned and operated businesses (Pistrui, Huang, Oksoy, Jing, \& Welsch, 2001).

\section{Research Design}

The authors conducted a survey of 1,440 MREs in seven cities in China. A 10-question instrument was developed and translated into Mandarin. Surveys were administered in person during a six-week period in June and July of 2016. Surveys were administered in the cities of Xi'an, Lanzhou, Beijing, Shenzhen, Fangchenggang, Chengdu, and Jinchang. The cities were chosen to provide geographic and economic diversity. Xi'an, Lanzhou, and Jinchang are located in northwest China, Beijing is located in north China, Shenzhen is in south China, Chengdu is located in the southwest, and Fangchenggang is located on the coast. Beijing and Shenzhen are first-tier cities, Chengdu and Xi'an are second-tier cities, Lanzhou is a third-tier city, and Fangchenggang and Jinchang are prefecture level cities.

The first part of the survey had two questions. MREs were classified into one of seven types of business: convenience store, souvenir, specialty retail, restaurant, vender, service, and household good stores. Second, MREs were asked whether sales and expenses were up, down, or stagnant compared to a year ago. The authors broke this into a question on whether sales were increasing, decreasing, or unchanged compared to last year and whether costs were increasing, decreasing, or unchanged compared to last year.

The second part of the survey focused on bank loans and credit card usage. Respondents were asked whether they had ever taken out a bank loan to support their business, how hard they thought it was to get 
access to credit, whether they wanted easier access to credit, and how they would use a loan (pay off debt or grow their business). Respondents were asked whether they accepted credit cards and for those who did not, the authors asked the reason. Respondents were also asked whether suppliers allowed them a grace period to pay for goods and services. The goal of this section was to gauge access to credit for MREs and how they were connected to the digital economy.

The final section of the survey asked respondents which business strategies they used in the past six months and what type of government program would be of the most help to them. These questions sought to better understand both how MREs are coping with a changing economy and what types of programs would be of the most assistance to them.

\section{Results}

The authors surveyed a total of 1,440 MREs (259 convenience stores, 115 souvenir, 177 specialty retail, 241 restaurants, 195 venders, 217 service providers, and 230 household good stores with 9 declining to be classified). A total of $38.3 \%$ of the businesses surveyed reported declining sales, $32.6 \%$ reported rising sales, and $29.1 \%$ reported flat sales. Of those surveyed, costs were lower than the previous year for $11.6 \%$, higher for $46.6 \%$, and flat for $41.7 \%$. A chi-square test to determine whether higher costs were associated with higher (or lower) sales determined that there was no significant relationship between the variables. MREs with rising costs did not report a reduction in sales and those with falling sales did not report higher input costs.

Despite anecdotal reports that small businesses have a very hard time getting bank loans, $41.6 \%$ of respondents reported that they did have a current loan from a bank to support their business. A chi-square test revealed differences in the types of MREs likely to have a bank loan, with souvenir stores and restaurants less likely to have a loan and venders much more likely to have a loan and convenience stores somewhat more likely to have a loan than would be expected. The generated chi-square of 17.543 was significant at the 0.01 level ( $p=0.007)$. Those who had a loan from a bank were (as expected) more likely to believe that bank loans were easier to get (chi-square of 26.837, $p=0.000$ ). Additionally, those MREs that had a loan from the bank were also more likely to accept bank cards than those that did not have a bank loan (chi-square of 48.271, $p=$ 0.000 ), likely because of their relationship with a bank that issued the loan or credit card.

A surprising 59.2\% of MREs accepted bank cards and almost half that did not; $20.1 \%$ of the total surveyed were considering accepting them in the future. Of the $40.8 \%$ that did not accept bank cards, $27 \%$ felt that the service fee was too high, $11 \%$ lacked easy access to the machine, $31.5 \%$ cited personal reasons, and $21.3 \%$ reported they did not know how to gain access. The adoption of bank cards by MREs is important since just a few years ago, studies found that acceptance of bank cards by retailers was limited. This phenomenon was in conflict with the desires of Chinese consumers who have gradually accepted the convenience of bank and credit cards (Li, Chao, Hui, \& Zhou, 2014).

Young consumers across China have begun to spend more using credit cards, providing "instant gratification" (Wang, 2009). A Nielsen survey found that $71 \%$ of shoppers in China's top-tier cities said they preferred bank cards over cash, compared with an average of roughly half for other countries they surveyed. Steidle found that income was negatively related to credit card debt. In other words, people with higher incomes are more likely to have lower credit card debt because they are presumably better able to pay off their credit card debt on time. The convenience of credit cards and the rise of rewards and loyalty programs serve as significant factors influencing consumers' decision whether to hold a credit card (Gan et al., 2016). The authors 
were surprised at the high rate of bank card acceptance by MREs given that the figures were quite low just a few years ago. Clearly, the situation has changed and future research should consider to what extent MREs find acceptance of credit cards to be beneficial to their bottom line.

Only $28.9 \%$ of MREs surveyed have a grace period before their suppliers demand payment for all goods. For $22.4 \%$, it varies by supplier, and $48.7 \%$ of those surveyed must pay immediately. Interestingly, this is actually good for MREs in general since the payment on accounts payable in China shifted upward from an average of 54 days in 2015 to 83 days in 2016. This can trigger a triangular debt crisis but the lack of accounts payable by so many helps insulate MREs from this problem.

Looking at different business strategies MREs might adopt, the authors found that in the six months prior to the survey being administered, $36.3 \%$ increased their hours of operation, $34.2 \%$ lowered prices, $13.6 \%$ reduced staff, $20.8 \%$ expanded their business, $30.0 \%$ advertised, and $41.9 \%$ ran a promotion. Using chi-square, the authors analyzed the effect of the type of business, whether they had a current bank loan, changes to sales, changes to costs, and whether they accepted bank cards in terms of any influence it might have on which business strategy they would employ.

For type of business, two chi-squares were significant at the 0.01 level. For increasing their hours of operation, the authors found that venders and service were more likely to adopt this strategy than expected and home suppliers were less likely to adopt this strategy (chi-square of 26.055, $p=0.000$ ). The authors also found a significant difference in whether they chose to advertise in the previous six months. Restaurants were more likely than expected to adopt this strategy and convenience stores and venders were less likely than expected (chi-square of 17.590, $p=0.007$ ). The authors looked for differences in business strategy by whether the MREs had a current bank loan but found no significant differences at the 0.01 level.

MREs did respond differently depending on whether sales rose or fell compared to the previous year. For MREs that experienced lower sales, they were more likely to lower prices (chi-square of $31.840, p=0.000$ ), less likely to expand their business (chi-square of $14.810, p=0.001$ ), and less likely to advertise (chi-square of $10.000, p=0.007)$. For MREs that reported higher costs than the previous year, there were no significant differences in the types of business strategy they would adopt. Finally, the authors looked whether MREs that accept bank cards are different in the types of business strategies they adopt compared to MREs that do not accept bank cards. The data revealed three key differences. Those that accepted bank cards were more likely to have increased their hours of operation (chi-square of $18.329, p=0.000$ ) and also more likely to have run a promotion (chi-square of $11.340, p=0.003$ ). In terms of advertising, those that are not currently accepting bank cards but are considering it, are significantly more likely to advertise than expected (chi-square of $36.325, p=$ $0.000)$.

The final question the authors asked was what type of government program would most help a business such as yours. Tax breaks for companies like mine was favored by $45 \%$. The $20.9 \%$ wanted subsidies for consumers to encourage spending, $18.5 \%$ wanted lower rates on bank loans, and $15.6 \%$ wanted better access to loans for companies like mine.

\section{Conclusions}

While much has been reported about China's slowing economy in general, comparatively little has been written about how this is affecting SMEs and virtually no studies exist looking at the effects of the slowing economy on MREs. These very small businesses are often overlooked but are an important part of the retail 
sector. As entrepreneurship in China continues to grow, this sector will become even more important. This study provides an early look at how MREs are faring in a slowing Chinese economy.

At one level, it may seem surprising that they are generally doing well overall and less than $40 \%$ are experiencing slower sales. This is likely because the slowdown of the economy has been sharpest in the extractive mining industry, the manufacture of steel and related industries. Smaller retail enterprises appear to have been less impacted. This is not entirely surprising. Many of the retail services and products MREs sell (e.g. haircuts, inexpensive meals for workers, etc.) are less prone to economic slowdowns. The larger than expected percentage of MREs reporting they have a bank loan is surprising. It runs counter to most accounts and raises questions as to why the results are not in line with what would be expected. Three possibilities emerge. It is well established that state-run banks have been directed (or at a minimum encouraged) to issue loans to state-run firms. First, it is possible that changes banks have enacted during the past several years to become more orientated toward service have resulted in more loans being given to small businesses than previously thought. Second, it is possible that banks have been giving out loans to both preferred state-run firms and small loans to MREs. Third, it is possible that respondents conflated the question "Do you currently have a loan from the bank to support your business?" with a broader question of whether they have a loan from any entity to support their business. Additional research will be needed to tease out which of the three possibilities is supported by evidence.

The adoption rate of bank cards by MREs is very impressive, compared to research conducted just three years ago. There is an explosion of a non-cash economy and it appears that MREs are more sophisticated in adopting new technology than some may have previously thought. For those that do not yet use bank cards, almost half plan to do so in the future. This finding is encouraging but was unexpected. Future surveys of MREs should include a question on whether the adoption of credit cards was a strategy put in place to increase or to maintain sales to better judge how quickly bank card acceptance is for retail business success. For those that do not yet accept bank cards, over 20\% report that they do not know how to gain access. It appears that banks, which increasingly are moving to seek profits from services would benefit from an information campaign aimed at MREs to better educate them in how to access bank card machines.

While differences were noted in which MREs adopted different business strategies, the most popular strategy overall was to run a promotion (41.9\%). Between 30 and 39 percent of MREs increased their hours of operation $(36.3 \%)$, lowered prices $(34.2 \%)$, or advertised $(30.0 \%)$. The two least popular strategies were to expand the business $(20.8 \%)$ or to reduce staff $(13.6 \%)$. Changes to the structure of the business are less popular business strategies in today's China for MREs and they seem to be adopting aggressive strategies to lure business and remain convenient for their customers.

The authors were surprised to see "tax breaks for companies like mine" $(45.0 \%)$ being the most popular government program to provide help for MREs. This runs counter to the image purported by some that these micro-businesses operate their business in a grey economy and seek to avoid paying taxes. Their desire for lower rates is a clear indication that these micro-businesses are paying their taxes and that the Chinese government is doing an effective job of collecting taxes on retail sales, even at MREs. The two least popular choices for a program to help MREs were "lower rates on bank loans" $(18.5 \%)$ and "better access to loans for companies like mine" $(15.6 \%)$. Both of these suggest that loans are far more common for small companies than it is commonly suggested. Lower rates are only useful if you have access to credit. The authors expected this to be the least popular response. The authors' expectation was better access to loans to be among the top answers 
but only $15.6 \%$ of those surveyed identified it as the most pressing issue for their business.

This paper's findings suggest that: there may be some emerging changes in China's credit market; bank cards are much more ubiquitous than previously thought; MREs have better access to credit than previously imagined by most; and the story of a slowing Chinese economy is much less uniform than previously imagined. Given how few studies exist on Chinese MREs, more field work is needed to confirm these findings. Although the authors conducted 1,440 surveys in seven Chinese cities, there are not enough studies done on this subject to know how representative these findings are.

\section{References}

2016 present situation analysis of China's retail industry and trend of development. (2016). Retrieved from http://www.chyxx. com/industry/201609/447043.html

BBC News. (2017). China's economy grows 6.7\% in 2016. Retrieved from http://www.bbc.com/news/ business-38686568

CBRC (China Banking Regulatory Commission). (2006). Strengthening regulation, improving city commercial bank's reform and development.

China Daily. (2015). Loans to small businesses rise by 3.08 t yuan in 2014. Retrieved from http://www.chinadaily.com. $\mathrm{cn} /$ china/2015twosession/2015-03/06/content_19744200.htm

China retail sales. (2017). Retrieved from http://www.tradingeconomics.com

Dudovsky, J. (2012). SMEs in China: Overview. Retrieved from http://research-methodology.net/small-and-medium-enter prises-in-china-overview/

Feng, Q. (2016). 2015 China's catering industry get out of the trough and entered a new stage. Economic Daily News.

Gai, H. (2015). Chinese convenience store: Growing against economy trend. Retrieved from http://www.eeo.com.cn/2015/ 0304/272971.shtml

Gan, C. E., Cohen, D. A., Hu, B. D., Tran, M. C., Dong, W. K., \& Wang, A. (2016). The relationship between credit card attributes and the demographic characteristics of card users in China. International Journal of Bank Marketing, 34(7), 966-984.

IFeng News. (2013). Small micro enterprises accounted for over $90 \%$ of the total number of Chinese companies products and services of GDP (translated from Mandarin). Retrieved from http://wallstreetcn.com/node/272959

J.P. Morgan. (2016). J.P. Morgan survey: China's currency reforms had biggest impact on business, treasurers say. Retrieved from http://www.jpmorganchina.com.cn/country/cn/zh/detail/1320553031109

Li, S., Chao, X. Hui, L., \& Zhou, Z. F. (2014). Research on simulation of credit risk of credit card based on multi-agent. Procedia Computer Science, 31, 517-522.

Li, Y., Guo, H., Liu, Y., \& Li, M. F. (2007). Incentive mechanisms, entrepreneurial orientation, and technology commercialization: Evidence from China's transitional economy. Product Innovation Mangement, 25(1), 63-78.

Liu, C. Y., \& Huang, X. (2016). The rise of urban entrepreneurs in China: Capital endowments and entry dynamics. Growth and Change, 47(1), 32-52.

Liu, X. F. (2008). SME development in China: A policy perspective on SME industrial clustering. In H. Lim (Ed.), SME in Asia and globalization (pp. 37-68). ERIA Research Project Report 2007-5. Retrieved from http://www.eria.org/SME\%20 Development\%20in\%20China_A\%20Policy\%20Perspective\%20on\%20SME\%20Industrial\%20Clustering.pdf

$\mathrm{Mu}$, Y. B. (2003). Impediments to SME access to finance and credit guarantee schemes in China. SSRN Electronic Journal. Retrieved from http://dx.doi.org/10.2139/ssrn.486204

Pistrui, D., Huang, W., Oksoy, D., Jing, Z., \& Welsch, H. (2001). Entrepreneurship in China: Characteristics, attributes, and family forces shaping the emerging private sector. Family Business Review, 14(2), 141-152.

Ren, D. (2016). China's VAT tax reforms are pushing small businesses to the brink. Retrieved from http://www.scmp.com/ business/china-business/article/2024061/chinas-vat-tax-reforms-are-pushing-small-businesses-brink

Shi, H., Peng, S. Z., Liu, Y., \& Zhong, P. (2008). Barriers to the implementation of cleaner production in Chinese SMEs: Government, industry and expert stakeholders' perspectives. Journal of Cleaner Production, 16(7), 842-852.

Siu, W.-S. (2001). Small firm marketing in China: A comparative study. Small Business Economics, 16(4), 279-292.

Tsao, R. (2015). One Belt One Road. Chinese American Forum, 31(1), 11-14. 
University of Pennsylvania's Warton School. (2015). China in 2015: Gauging the new normal. Retrieved from http://knowledge. wharton.upenn.edu/article/gaging-the-new-normal-in-china/

Waldmeir, P. (2016). China data signal deepening slowdown. Retrieved from https://www.ft.com/content/51fa4cfe-df5b-11e5b072-006d8d362ba3

Wall Street. (2016). The State Council: To encourage retail online mergers and acquisitions online. Retrieved from http://wallstreetcn.com/node/272959

Wang, C. L. (2009). Little emperors! The future of China's consumer market. Young Consumers, 10(2), 95-97.

Wang, H. (2004). Financing conditions and institutional failure of small and medium-sized enterprises financing in transitional China. Harvard Asia Quarterly, 8(4), 35-46. 